\title{
Immunohistochemical Study of Metallothionein Isoform II in Hyperplastic,Dysplastic and Neoplastic Prostatic Lesions
}

\author{
Sonia L. El Sharkawy; Marwa A. El Shaer; Manal A. Badawi \\ and Mohamed H. kobeisy* \\ Pathology Department, National Research Centre; \\ *Pathology Department, National Institute of Nephrology and Urology.
}

\begin{abstract}
Metallothioneins (MTs) constitute a family of several intracellular, low molecular-weight proteins with a high affinity to various heavy metals. They are involved in metalloregulatory functions such as cell proliferation, growth, and differentiation. The goals of the present study were to investigate the expression of MT in hyperplastic, dysplastic and neoplastic prostatic lesions and to correlate its expression with histologic grade of prostatic carcinoma.

This study was performed on Formalin fixed and paraffin embedded tissue blocks from 8 patients with benign prostatic hyperplasia $(\mathrm{BPH}), 6$ patients with prostatic intraepithelial neoplasia (PIN) and 30 patients with prostatic carcinoma (PC) using streptavidin-biotin technique. The histologic grade was defined and the carcinoma cases were divided into 8 low grade (Gleason 2-4), 12 moderate grade (Gleason 5-6) and 10 high grade (Gleason 7-10) carcinoma.

Normal and benign prostatic tissues showed patchy MT staining of epithelial cells. All cases of PIN, 20 out of 30 PC cases (66.7\%) showed positive staining for MT. MT expression significantly increased from low to high grade tumours. The proportion of MT positively stained cells was directly correlated with histologic grade of PC. The epithelial cells lack uniformity in staining intensity, but the percentage of strongly positive cells increased with increasing the histologic grade of PC.

The high incidence of MT expression in PIN in this study suggests that it is associated with early prostate tumorigenesis. Also MT expression was directly correlated with histologic grade of PC suggesting that MT may be a useful marker for predicting prognosis of cancer prostate.
\end{abstract}

Key words: Prostate, Benign prostatic hyperplasia, Prostatic intraepithelial neoplasia, Prostatic carcinoma, Metallothionein, Immunohistochemistry.

\section{Introduction}

Prostatic carcinoma is the most prevalent cancer among men in the western world. Preneoplastic lesions, known as prostatic intraepithelial neoplasia (PIN), have been found in men as early as 20 years of age and are commonly observed in men $>50$ years of age. PIN lesions are thought to be precursors of invasive cancer prostate in which incidence significantly increases in the sixth decade of life (Sakr et al., 1993; Green et al., 2001 and Calvo et al., 2003). Aging, genetic factors, environmental carcinogens, and steroid hormone levels are factors that have been associated with the development of prostatic cancer (Wild et al., 2001).
Metallothioneins (MTs) constitute a family of several intracellular, low molecular-weight proteins with a high affinity to various heavy metals such as zinc, cadmium, copper, mercury and platinum (Woo et al., 1997). Different isoforms ( 0 to IV) of MT have been identified. MT-I and II are major isoforms in mammalian tissues. They are believed to serve as important role in the homeostasis of essential metals such as $\mathrm{Zn}$ and $\mathrm{Cu}$ during growth and development, as well as in the detoxification of heavy metals such as $\mathrm{Cd}$ and $\mathrm{Hg}$, rendering the MTs important mediators and attenuators of heavy 
metalinduced toxicity (Bier et al., 1994; Sens et al., 2000 and Lynn et al., 2003).

It was found that MTs are involved in metalloregulatory functions such as cell proliferation, growth, and differentiation. In recent years, MT expression has been linked with carcinogenesis, resistance to cancer therapy, and tumour progression (Tan et al., 1999; Tai et al., 2003 and Surowiak et al., 2004). Immunohistochemically detected MT is not usually found in normal tissues except in myoepithelial cells of the breast, and epithelial cells of the kidney and thyroid gland (Lynn et al., 2003).

MT overexpression occurs frequently in human malignant tumours, but the underlying mechanism is unknown (Jasani et al.,1998). Several lines of evidence suggest that MT may be involved in cell proliferation and differentiation in carcinogenesis (Cherian et al., 1993; Jasani et al., 1998 and Meining et al.,1998). Many studies have shown an association of metallothionein overexpression with tumour type and grade (Garrett et al., 2000). It has been expressed in various types of human cancer such as colorectal (Ofner et al., 1994 and Jasani et al., 1998), bladder (Somji et al., 2001) and breast cancers (Surowiak et al., 2002 and Tai et al., 2003).

The goals of the present study were to investigate the expression of MT in hyperplastic, dysplastic and neoplastic prostatic lesions and to correlate its expression with histologic grade of prostatic carcinoma.

\section{Material and Methods}

Formalin fixed and paraffin embedded tissue blocks from 8 patients with BPH, 6 patients with PIN and 30 patients with PC were collected from National Institute of Urology and Nephrology. They were obtained by radical prostatectomy, transurethral resection or prostatic needle biopsy. Five specimens composed of normal prostate adjacent to tumours were included in this study. The Gleason system was used for histological grading of malignant tumours (Gleason, 1977). According to Xiang-Hua et al. (1996), the cases were classified as 8 low grade
(Gleason score 2-4), 12 moderate grade (Gleason score 5-6) and 10 high grade (Gleason score 7-10).

\section{Metallothionein immunohistochemical staining:}

Streptavidin-biotin technique was used to investigate MT expression. Tissue samples were fixed in $10 \%$ buffered formalin for 24 hours. Four micron-thick sections were cut. After deparafinization and hydration of tissue sections, they were incubated for 30 minutes in $0.3 \%$ hydrogen peroxide to quench endogenous peroxidase activity. Antigen retrival was done by microwave pretreatment for 10 minutes in $0.01 \mathrm{M}$ citrate buffer. The sections were incubated for 20 minutes with normal blocking serum to suppress non-specific binding of immunoglobulin. The tissue sections were incubated at $4^{\circ} \mathrm{C}$ overnight with antimetallothionein monoclonal antibody (Dako- MT, E9; from Dako Corporation) which react with metallothionein isoform I and II at a dilution 1:50. These steps were followed by a 30 minutes incubation with biotinylated horse anti-mouse antibody at room temperature, avidin-biotin peroxidase complex for 50 minutes at room temperature and finally diamiobenzidine (DAB) for 3-5 minutes. The slides were counterstained with hematoxylin, dehydrated and mounted. In each MT staining patch normal kidney tissue was included as a positive control. Positive staining was indicated by cytoplasmic or nuclear and cytoplasmic brown colouration,. Negative control was obtained by omitting the primary antibody.

Metallothionein immunostaining results were scored 0--no, 1--less than $25 \%$, $2--25$ to $50 \%$ and 3--more than 50\% staining cells (Xiang-Hua et al., 1996). The results were judged positive if more than $25 \%$ of the tissue section stained. Staining intensity was recorded semiquantitatively as mild $(+)$, moderate $(++)$ or strong $(+++)$ according to Somji et al., (2001)

Statistical analysis:

Difference in distribution of variables between groups were tested using Chisquare test. $\mathrm{P}$ value less than 0.01 was considered statistically significant. 


\section{Results}

A total of 44 prostatic lesions were evaluated for MT immunoreactivity. Normal and benign prostatic tissues showed patchy MT staining of epithelial cells (figure 1). All cases of PIN, 20 out of 30 PC cases $(66.7 \%)$ showed positive staining for MT (more than $25 \%$ of cells). Although some cells showed only cytoplasmic staining, most cancer cells showed cytoplasmic and nuclear staining. Only 1 case of PIN and 5 cases of PC showed positive staining of the basement membrane surrounding the cancer cells (figures $2 \& 4$ ).

Table (1) showed the correlation of MT expression with histologic grade of PC. It was found that MT expression significantly increased from low $(37.5 \%)$, to moderate $(66.7 \%)$ to high grade tumours $(90 \%)$ $(\mathrm{P}<0.01)$.
Table (2) showed the correlation of the proportion of positively stained cells and histologic grades of PC. It was found that $76-100 \%$ of cells were positively stained in 8 high grade (88.8\%) and 5 moderate grade tumours $(62.5 \%)$. On the other hand 2 cases of low grade $(66.7 \%)$ and one case of moderate grade $(! 2.5 \%)$ showed positive staining of $26-50 \%$ of cells. These results revealed that the proportion of MT positively stained cells was directly correlated with histologic grade of $\mathrm{PC}(\mathrm{P}<0.01)$.

As regard MT staining intensity, it was found that the epithelial cells lack uniformity in immunoreaction, some stained strongly while others stained weakly and the percentage of strongly positive cells increased from low grade to high grade PCs (figures 3-5).

Table (1): Correlation of MT expression and histologic grade of PC.

\begin{tabular}{|l|l|l|c|l|l|}
\hline $\begin{array}{l}\text { MT } \\
\text { expression }\end{array}$ & Low grade & Moderate grade & High grade & Total & P-value \\
\hline+ ve & $3(37.5 \%)$ & $8(66.7 \%)$ & $9(90.0 \%)$ & $20(66.7 \%)$ & \\
- ve & $5(62.5 \%)$ & $4(33.3 \%)$ & $1(10.0 \%)$ & $10(33.3 \%)$ & $<0.01$ \\
Total & $8(100 \%)$ & $12(100 \%)$ & $10(100 \%)$ & $30(100 \%)$ & \\
\hline
\end{tabular}

Table (2): Correlation of the proportion of positively stained cells and histologic grade of positively stained $\mathrm{PC}$ cases.

\begin{tabular}{|l|l|l|l|l|l|}
\hline $\begin{array}{l}\text { \% of } \\
\text { +ve cells }\end{array}$ & Low grade & Moderate grade & High grade & Total & P-value \\
\hline $26-50 \%$ & $2(66.7 \%)$ & $1(12.5 \%)$ & $0(0.0 \%)$ & $3(15.0 \%)$ & \\
$51-75 \%$ & $1(33.3 \%)$ & $2(25.0 \%)$ & $1(11.1 \%)$ & $4(20.0 \%)$ & $<0.01$ \\
$76-100 \%$ & $0(0.0 \%)$ & $5(62.5 \%)$ & $8(88.9 \%)$ & $13(65.5 \%)$ & \\
Total & $3(100 \%)$ & $8(100 \%)$ & $9(100 \%)$ & $20(100 \%)$ & \\
\hline
\end{tabular}




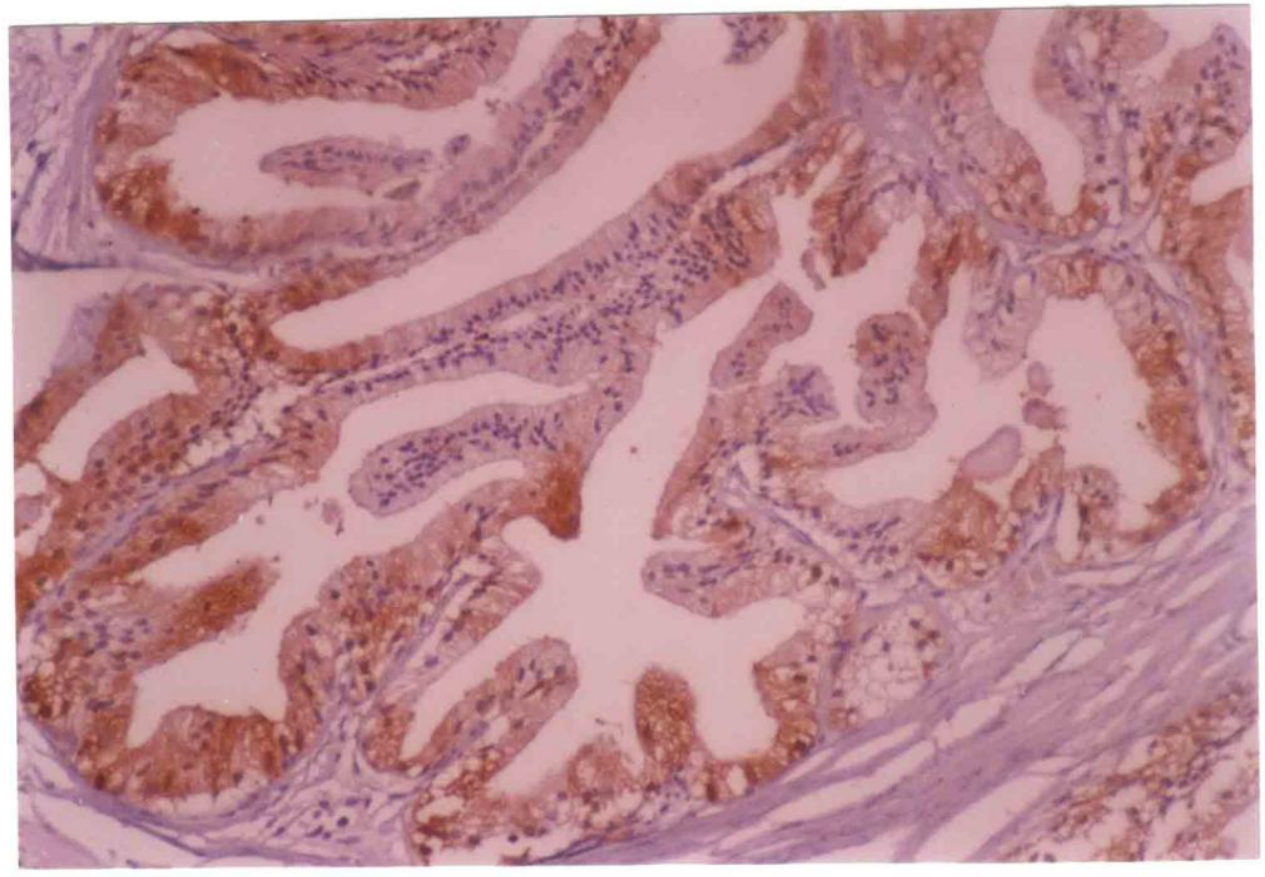

Fig. (1): Benign prostaic hyperplasia showing patchy cytoplasmic staining for MT. (Immunoperoxidase X150).

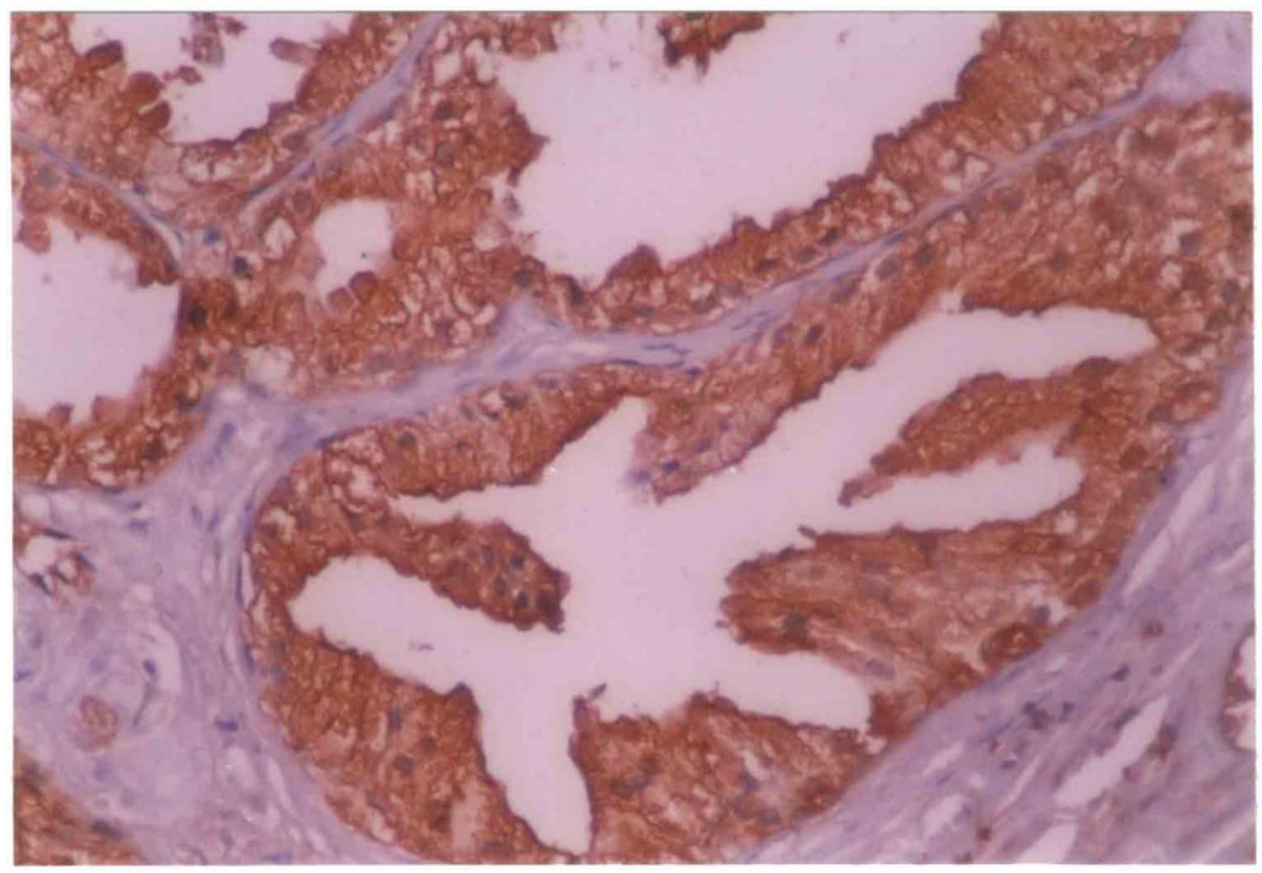

Fig. (2): Prostatic intraepithelial neoplasia with diffuse cytoplasmic and focal membranous staining for MT. (Immunoperoxidase X300). 


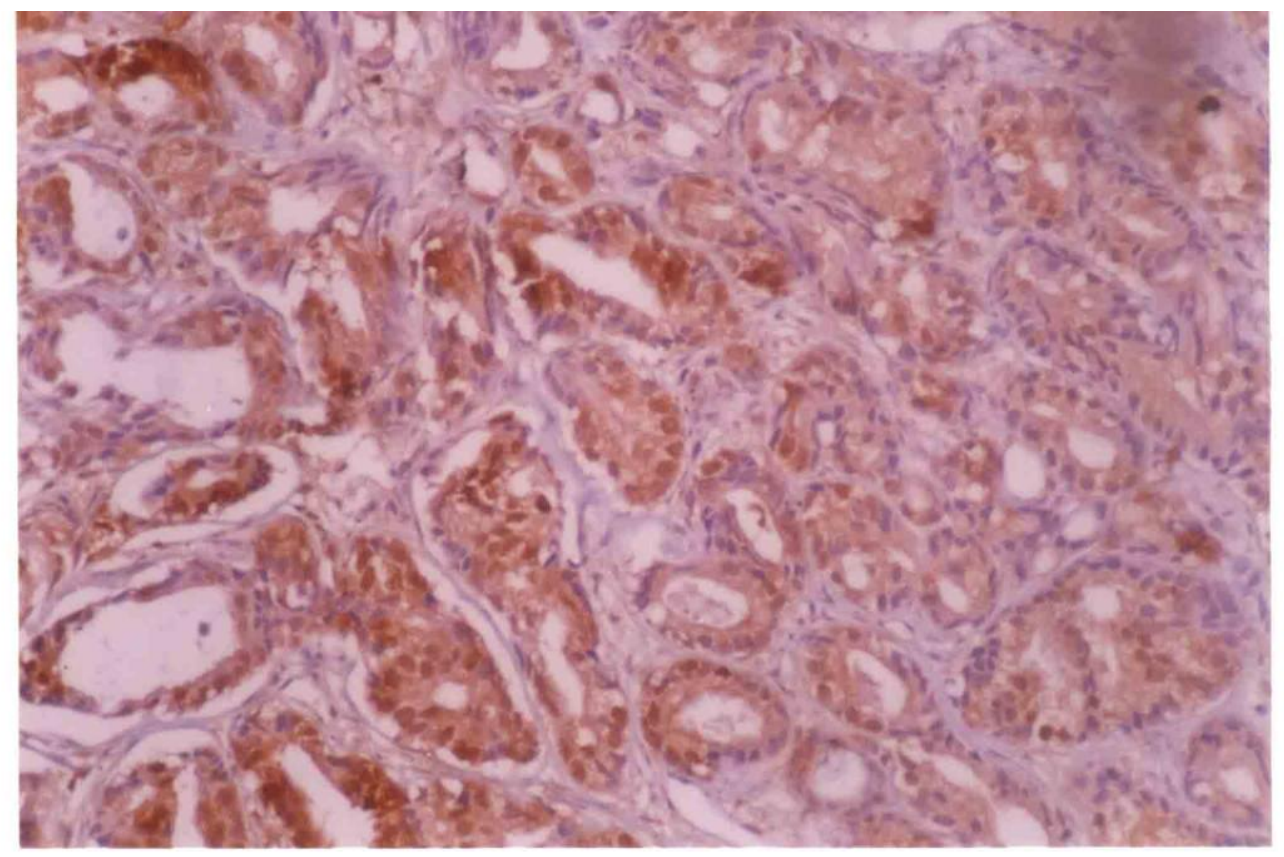

Fig. (3): Low grade prostatic carcinoma revealing cytoplasmic staining which lacks uniformity of staining intensity.

(Immunoperoxidase X300).

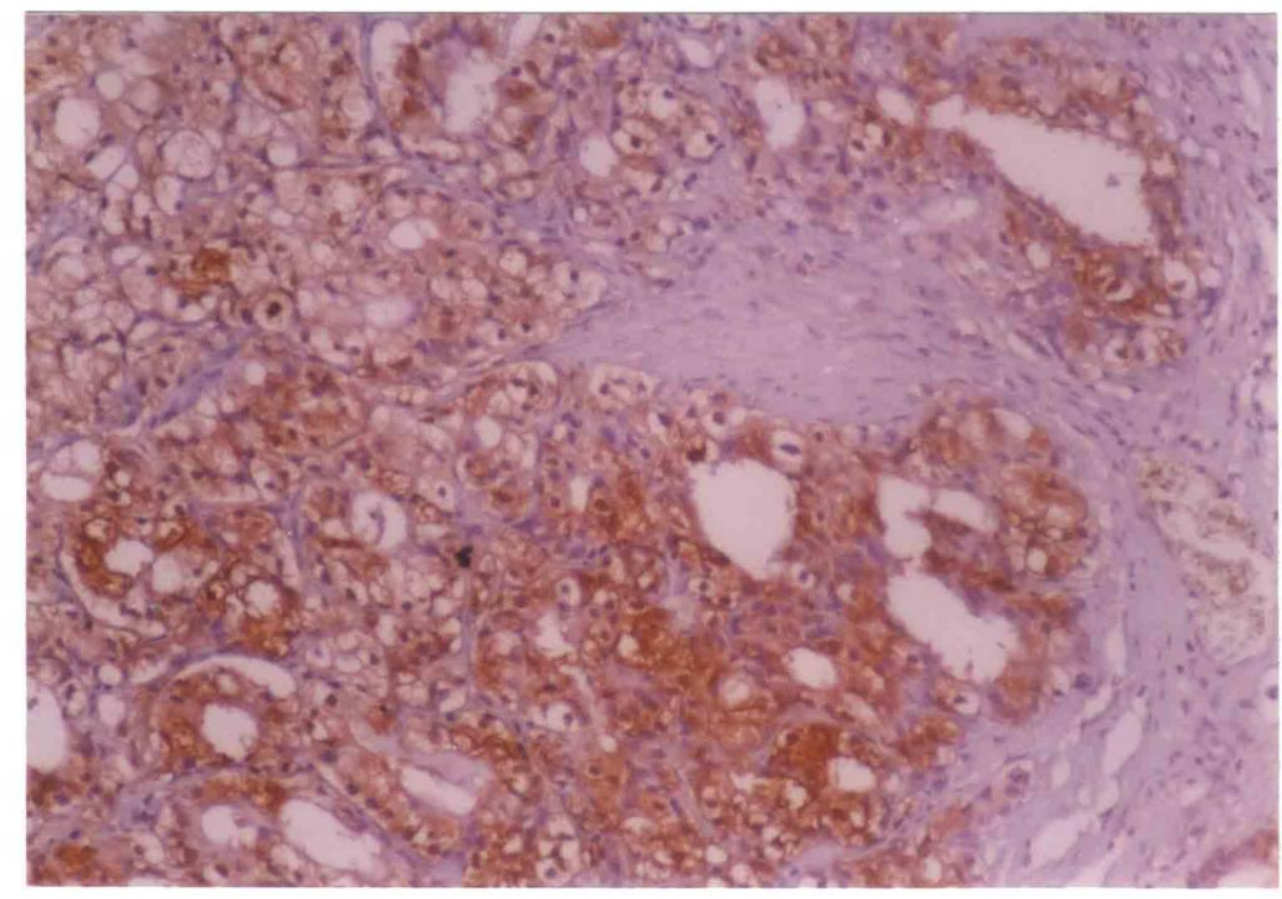

Fig. (4): Moderate grade prostatic carcinoma showing cytoplasmic, membranous and focal nuclear staining for MT. (Immunoperoxidase X300). 


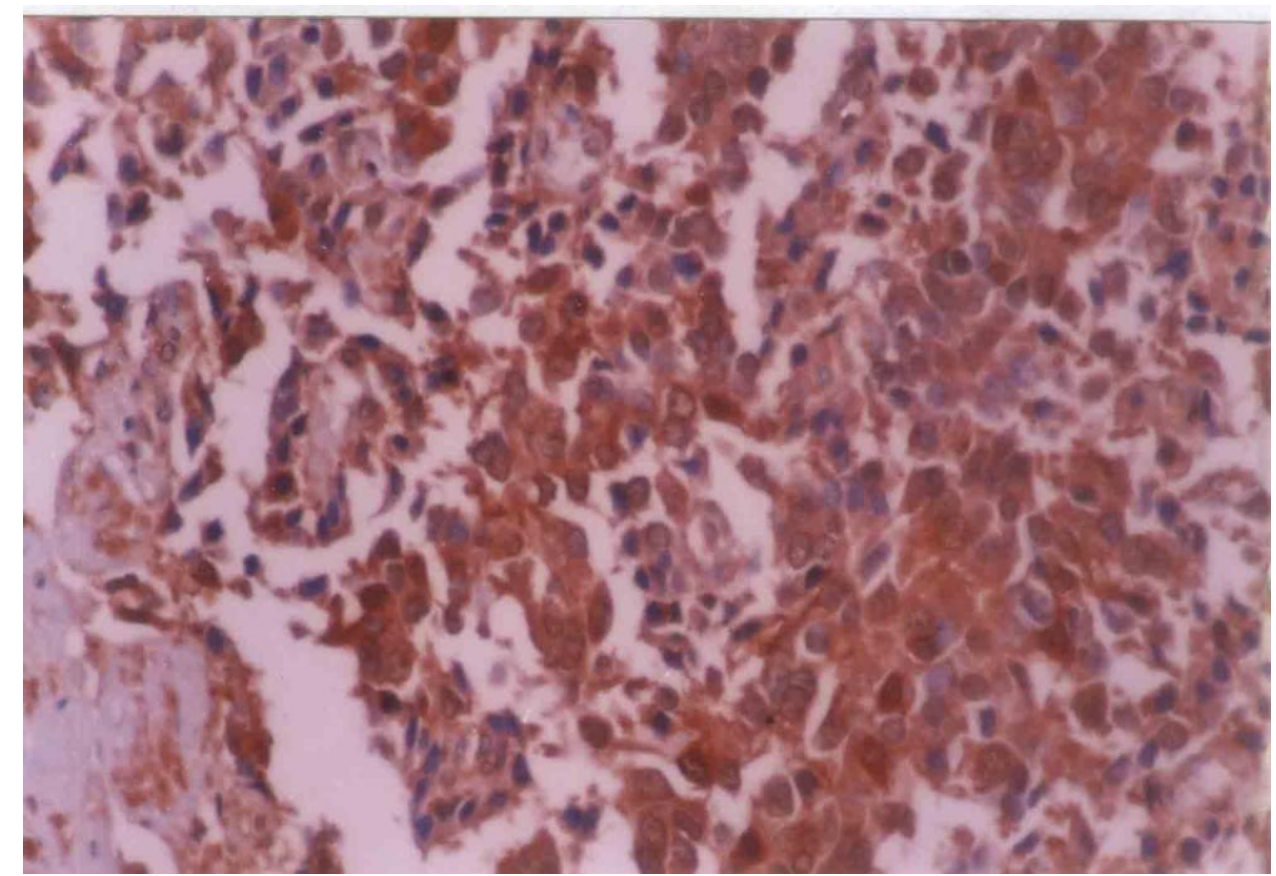

Fig. (5): High grade prostatic carcinoma revealing cytoplasmic staining for MT with high proportion of strongly stained cells.

(Immunoperoxidase X300).

\section{Discussion}

Prostatic glands contain heavy metals such as zinc and cadmium, and epidemiological studies showed that both metals were associated with prostate cancer development (Hasumi et al., 2003). Metallothionein (MT) is a low-molecular weight cystein-rich protein, which has the ability to bind and sequestrate heavy metal ions. Its synthesis is induced in a variety of tissues by these metal ions, as well as by endogenous factors such as glucocorticoids, interferon, interleukin-1 and vitamin D (Ioachim et al., 2001). Several lines of evidence have indicated that MT may play a role in carcinogenesis and in drug resistance of tumours (Moussa et al., 1997 and Surowiak et al., 2004).

Few results previously evaluated MT expression in prostatic lesions with conflicting results. The present study aimed to study the expression of MT in benign prostatic hyperplasia (BPH), prostatic intraepithelial neoplasia (PIN) and prostatic carcinoma (PC) to evaluate its role in prostatic carcinogenesis. Also MT expression was correlated with histologic grade of prostatic carcinoma to study its usefulness as an indicator of aggressive behaviour of the tumours.

In the present study, normal and benign prostatic tissue showed patchy MT staining of epithelial cells. These results were in agreement with previous observations of Moussa et al. (1997) and Zhang et al. (2000)). Also MT was increased in PIN and further increased in a highly variable fashion in PC. These results were in accordance with the study of Garrett et al.(1999).

The present study showed that MT expression was observed in $66.7 \%$ of PC. This result is higher than the study of Zhang et al., (2000) in which MT was expressed in $33.3 \%$ only of PC cases. In contrast Moussa et al.(1997) showed that all tumour foci were positively stained for MT. These conflicting results may be explained by the differences in antibodies, methods and /or interpretation of immunostaining results.

Regarding the staining pattern, similar to previous findings of Moussa et al., (1997); Tekur and Ho (2002), most cancer 
cells revealed cytoplasmic and nuclear staining. Although MT is thought to be a cytoplasmic protein, many studies suggest that MT is present in the cytoplasm and nucleus of normal and malignant cells (Tohyama et al., 1993; Woo et al., 1997 and Ogra and Suzuki, 2000). It is known that subcellular localization of MT is regulated in cells undergoing proliferation, developmental progression, tumorigenesis and during the cell cycle (Ogra and Suzuki, 2000). In the present study, only one out of 6 cases of PIN and 5 out of 20 cases of PC showed positive staining of the basement membrane surrounding the cancer cells, this was in agreement with Zhang et al. study (2000) where 2 out of 15 cases of PC showed the same finding. It is well known that the glandular epithelial cells (normal cells, particularly the basal cells, or malignant cells) may participate in biosynthesis of the basement membrane. Consequently, this phenomenon may be regarded as an actively secretory result of the cancer cells (Zhang et al., 2000).

A close correlation of MT expression and invasive breast carcinoma with a poor prognosis (Fuentealba and Mullins, 1999; Surowiak et al., 2004 ), as well as tumour grade in breast carcinoma (Zhang et al.,2000) and bladder carcinoma (Lynn et al., 2003) has been reported. In this study MT expression was significantly correlated with the histologic grading of PC where its expression increased from low to moderate to high grade tumours. These results were in accordance with Zhang et al. (2000); Garrett et al. (2000) and Dutta et al. (2002). It was found also that the proportion of positively stained cells significantly correlated with histologic grade of PC. As regard MT staining intensity in the present study, the epithelial cells were lacking uniformity in immunoreaction where some stained strongly while others stained weakly and the percentage of strongly stained cells increased from low to high grade PC. This was in accordance Suzuki et al. study (1992). Generally, it is believed that anaplastic and aggressive tumours with more cellular metabolic activity may have greater zinc and metallothionein requirements (Ogunlewe and Osegbe, 1989).
Therfore this wide range of lacking uniformity of MT expression may result from changes in zinc or cadmium metalothionein in cancer prostate (Xiang-Hua et al., 1996).

Conclusion: The high incidence of MT expression in PIN in this study suggests that it is associated with early prostate tumorigenesis. Also MT expression was directly correlated with histologic grade of PC suggesting that MT may be a useful marker for predicting prognosis of cancer prostate.

\section{References}

1- Bier B.; Douglass-Jones A.; Totsch M.; Dockhorn-Dworniczak B. et al. (1994): Immunohistochemical demonstration of metallothionein in normal breast tissue and benign and malignant breast lesions. Breast Cancer Res. Treat., 30: 213.

2- Calvo A.; Xiao N.; Kang J.; Best C.J.; Leiva I.; Emmert-Buck M.R.; Jorcyk C. and Green J.E. (2003): Alterations in gene expression profiles during prostate cancer progression. Cancer Research 62 (15): 5325-5335.

3- Cherian M.G.; Huang P.C.; Klaassen C.D.; Liu Y.P. and Waalkes M.P. (1993): National Cancer Institute Workshop on the possible roles of metallothionein in carcino-genesis. Cancer Res., 53; 922928.

4- Dutta R.; Sens D.A.; Somji S.; Sens M.A. and Garrett S.H. (2002): Metallothionein isoform 3 expression inhibits cell growth and increases drug resistance of $\mathrm{PC}-3$ prostate cancer cells. Prostate, 52(2): 89-97.

5- Fuentealba I.C. and Mullins J.E. (1999): Immunohistochemical demonstration of metalothionein in benign and malignant canine mammary tumours. Histol. Histopathol., 14(1): 51-61

6- Garrett S.H.; Sens M.A.; Shukla D.; Flores L.; Somji S.; Todd J.H. and Sens D.A.(2000): Metallothionein isoform 1 and 2 gene expression in the human prostate: downregulation of MT-1X in advanced prostate cancer. Prostate, 1;43(2): 125-35. 
7- Garrett S.H.; Sens M.A.; Shukla D.; Nestor S.; Somji S.; Todd J.H. and Sens D.A.(1999): Metallothionein isoform 3 in the human prostate and cancer derived-cell lines. Prostate, 1;41(3): 196-202.

8- Gleason D.F. (1977): Histological grading and clinical staging of prostatic carcinoma. In: Urologic Pathology: The prostate. Edited by M. Tannenbaum. Philadelphia: Lea and Febiger, chapt. 9, pp. 171-198.

9- Green R.T.; Hill-Harmon M.B.; Murry T. and Thun M. (2001): Cancer statistics. CA - Cancer J. Clin., 51-36.

10-Hasumi M.; Suzuki K.; Matsui H.; Koike H.; Ito $\mathrm{K}$ and Yamanaka $H$. (2003): Regulation of metallothionein and zinc transporter expression in human prostate cancer cells and tissues. Cancer Lett., 28; 200(2): 18795.

11-Ioachim E.E.; Charchanti A.V.; Stavropoulos N.E.; Athanassion E.D.; Michael M.C. and Agnantis N.J. (2001): Localization of metallothionein in urothelial carcinoma of the human urinary bladder: an immunohistochemical study including correlation with HLADR antigen, P53 and proliferation indices. Anticancer Res., 21(3B): 1757-1761.

12-Jasani B.; Campbell F.; Navabi H.; Scchmid K.W. and Williams G.T. (1998): Clonal overexpression of metallothionein is induced by somatic mutation in morphologically normal colonic mucosa. J Pathol., 184(2): 144-147.

13-Lynn N.N.K.; Howe M.C.; Hale R.J.; Collins G.N. and O'Reilly P.H. (2003): Over expression of metallothionein predicts resistance of transitional cell carcinoma of bladder to intravesical mitomycin therapy. The Journal Of Urology, 169: 721-723.

14-Meining A.; Hackelsbberger A.; Daenecke C.; Stotte M.; Bayerdorffer E. and Ochsenkuhn T. (1998): Increased cell proliferation of the gastric mucosa in first-degree relatives of gastric carcinoma patients. Cancer (Phila.), 83: 876-881.

15-Moussa M.; Kloth D.; Peers G.; Cherian M.G.; Frei J.V. and Chin J.L. (1997): Metallothionein expression in prostatic carcinoma: correlation with Gleason grade, pathologic state, DNA content and serum level of prostate-specific antigen. Clin Invest. Med., 20(6): 371380.

16-Ofner D.; Majer H.; Riedmann B.; Bammer T.; Rumer A. and Winde G. (1994): Immunohistochemical metallothio-nein expression in colorectal adenocarcino-ma: correlation with tumour stage and patient survival. Virchows Arch., 425: 491-498.

17-Ogra Y. and Suzuki K.T. (2000): Nuclear trafficking of metallothionein; possible mechanisms and current knowledge. Ceel. Mol. Biol., 46: 357364.

18-Ogunlewe J.O. and Osegbe D.N. (1989): Zinc and cadmium concentrations in indigenous blacks with normal, hyperplastic and malignant prostate. Cancer, 63: 1388.

19-Sakr W.A.; Haas G.P.; Cassin B.F.; Pontes J.E. and Crissman J.D. (1993): The frequency of carcinoma and intraepithelial neoplasia of the prostate in young male patients. J. Urol., 150: 379-385.

20-Sens M.A.; Somji S.; Lamm D.L.; Garre H.S.H.; Slovinsky F.; Todd J.H. and Sens D.A. (2000): Metallothionein isoform 3 as a potential biomarker for human bladder cancer. Environ.Health.Perspect. 108: 413-418.

21-Somji S.; Sens M.A.; Lam D.L.; Garrett S.H. and Sens D.A. (2001): Metallothionein isoform 1 and 2 gene expression in the human bladder: evidence for upregulation of MT-1X Mrna in bladder cancer. Cancer Detect. Preven., 25(1): 62-75.

22-Surowiak P.; Dziegiel P.; Matkowski R.; Kornafel J.; Wojnar A. and Zabe M. (2002): Immunohistochemical evaluation of metallothionein expression in myoepithelial cells of ductal mammary carcinoma and its relation to survival time: analysis of 7 years course of the disease. Folia. Hitochem. Cytobiol., 40(2): 199-200.

23-Surowiak P.; Paluchowski P.; Wysocka T.; Wojnar A. and Zabel M. (2004): Steroid receptor status, proliferation and metallothionein 
expression in primary invasive ductal breast cancers. Pathol Oncol Res., 10(40): 207-211.

24-Suzuki T.; Yamanaka H.; Nakajima K.; Suzuki K.; Kanatani K.; Kimura M.; Ohma C. and Otaki N. (1992): Immunohis-tochemical study of metallothionein in human seminal vesicles. Tohoku J Exp Med., June;167(2): 127-134.

25-Tai S.K.; Tan O.J.; Chow V.T.; Jin R.; Ones J.I.; Tan P.H.; Jayasurya A. and Bay B.H. (2003): Differential expression of metallothionein 1 and 2 isoforms in breast cancer lines with different invasive potential. Am J Pathol., 163(5): 2009.

26-Tan Y.; Sinniah R.; Bay B.H. and Sing G. (1999): Metallothionein expression and nuclear size in benign, borderline, and malignant serous ovarian tumours. J. Pathol., 189(1): 60-65.

27-Tekur S. and Ho S.M. (2002): Ribozome-mediated downregulation of human metallothionein II(a) induces apoptosis in human prostate and ovarian cancer cell lines. Molecular Carcinogenesis, 33(1): 44-55.

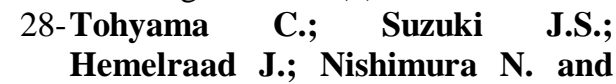

Nishimura H. (1993): Induction of metallothinein and its localization in the nucleus of rat hepatocytes after partial hepatectomy. Hepatology, 18: 1193-1199.

29-Wild C.P.; Andersson C.; O'Brien N.M.; Wilson L.; Wood J.A.(2001): A critical evaluation of the application of biomarkers in epidemiological studies on diet and health. Br. J. Nutr., 86: 37-53.

30-Woo, E.S.; Monks A.; Watkins S.C.; Wang A.S. and Lazo J.S. (1997): Diversity of metallothionein content and subcellular localization in the National Center Institute Tumour Panel. Cancer Chemother. Pharmacol., 41: 61-65.

31-Xiang-Hua X.H.; Li J. and Ikumasa T. (1996): Immunohistochemical localization of metallothionein in human prostate cancer. The Journal of Urology, 156(5): 1679-1681.

32- Zhang R.; Zhang H.; Wei H. and Luo X. (2000): Expression of metallothionein in invasive ductal breast cancer in relation to prognosis. $\mathbf{J}$ Environ Pathol Toxicol Oncol., 19(12): 95-97. 


\section{دراسة هستوكيميائية للميتالوثيونين-2 في إصابات البروستاتا

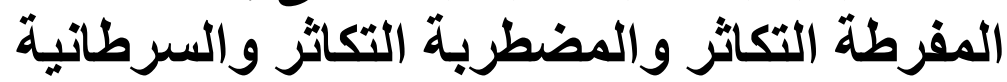

\section{سونيا لبيبب عبد الفتاح ـ مروه عبد المنعم الثاعر - منال عبد المجيذ بلوى ـ

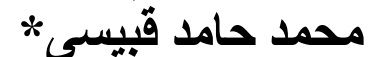

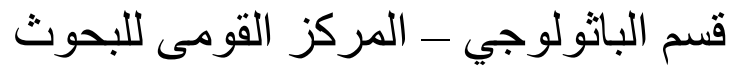 قسم الباثولوجي ـ المعهد القومي الامر اض الكلى و المسالك للك}

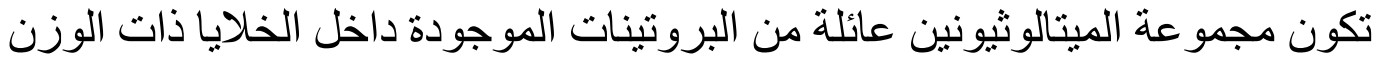

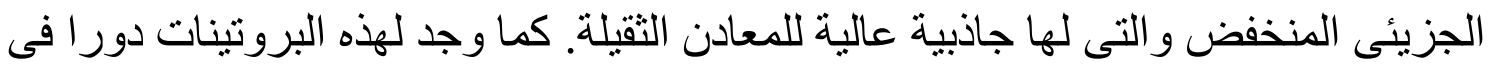

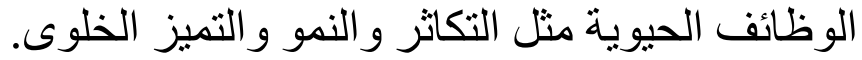

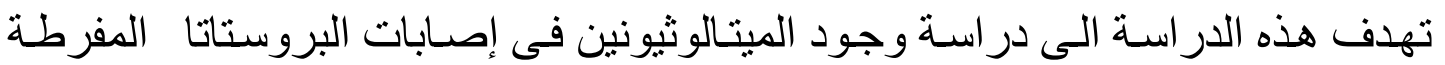

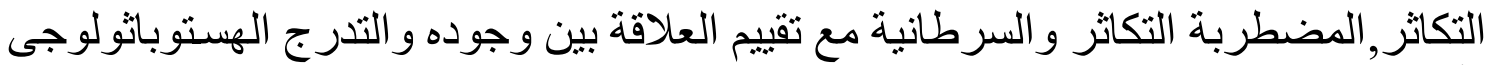
ل أور ام البروستاتا السرطانية.

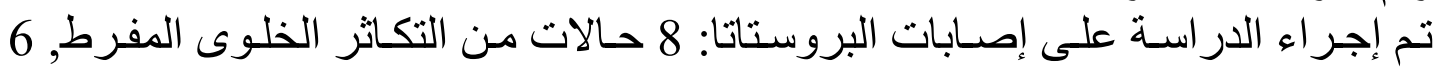

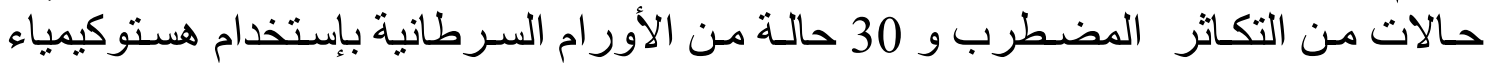

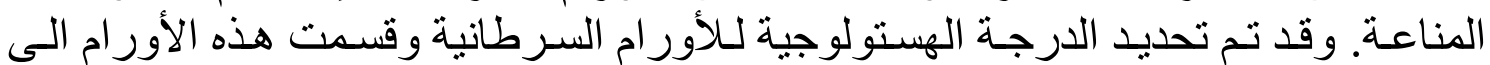

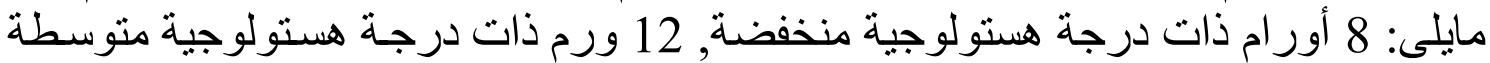

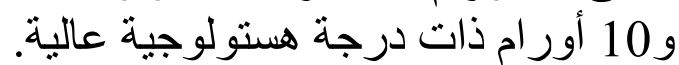

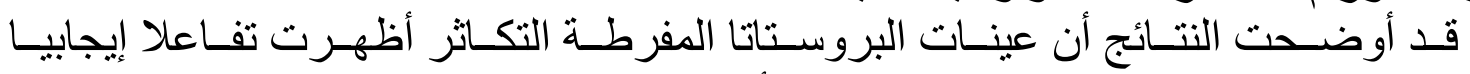

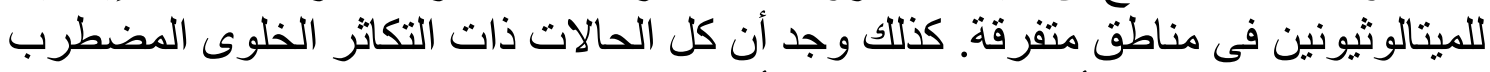

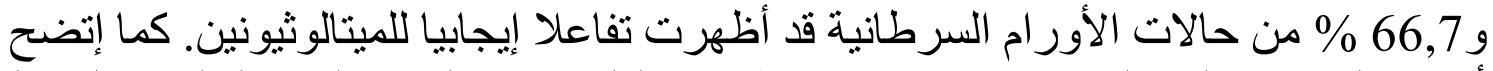

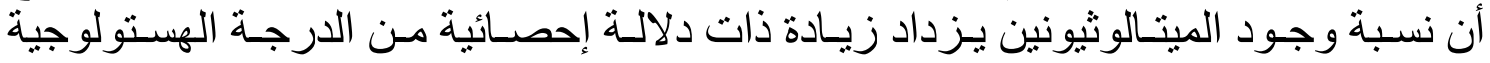

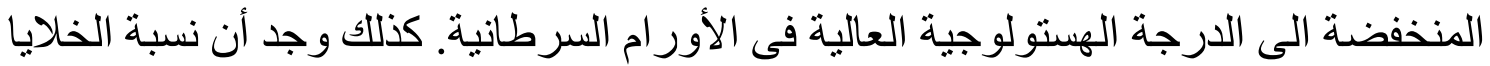

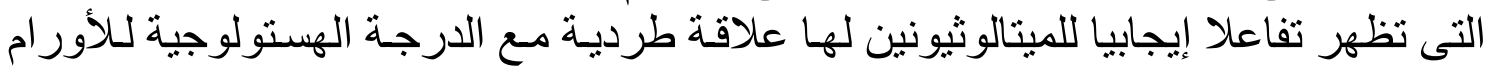




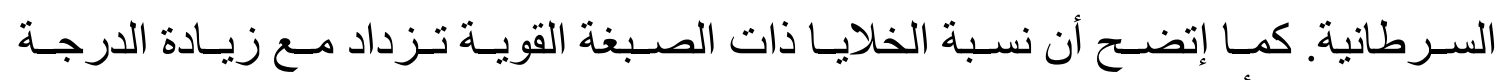
الهستولوجية للأورام.

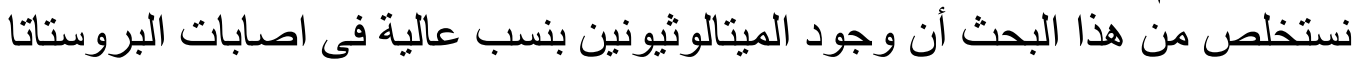

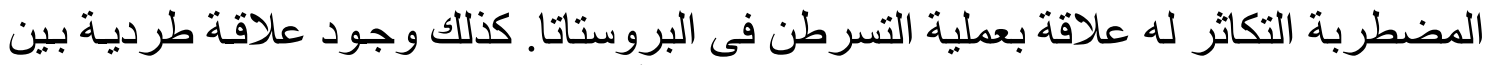

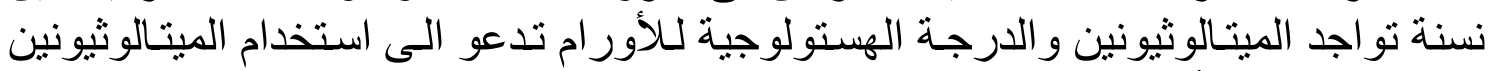
كدليل للتنبؤ بمآل أورام البروستين والبا السرطانية. 